\title{
Variance effective population size based on multilocus gamete frequencies in coniferous populations: an example of a Scots pine clonal seed orchard
}

\author{
JAROSŁAW BURCZYK \\ Department of Biology and Environment Protection, Pedagogical University, Chodkiewicza 30, \\ PL 85-064 Bydgoszcz 1, Poland
}

\begin{abstract}
The temporal method for estimating variance effective population size $\left(N_{\mathrm{e}}\right)$ based on allozyme multilocus gamete frequency data in coniferous populations is proposed. The method was applied to a Scots pine (Pinus sylvestris L.) seed orchard consisting of 32 clones (parents), and the genotypes of pollen gametes fertilizing $1280(N)$ viable seed embryos (progeny) were identified. The gametic frequency estimate of variance effective population size indicated that the progeny population (its part attributed to pollen contribution) was equivalent to 105.3 individuals in an idealized theoretical population, whereas the estimate based on allele frequencies (traditional method) was 156.7 individuals. However, the estimates did not differ statistically. The ratio $\hat{N}_{\mathrm{e}} / N$ was very low $(0.0823$ and 0.1224 for the gametic and allele frequency methods, respectively), indicating nonrandom contributions of male parents to the progeny generation. The advantages of using the gametic frequency estimates of variance effective population size instead of estimates based on allele frequencies are briefly discussed.
\end{abstract}

Keywords: isozymes, mating system, Pinus sylvestris L., pollen gamete genotypes, seed orchard, variance effective number.

\section{Introduction}

The effective population size is one of the important parameters of a mating system. Generally, it defines the number of individuals effectively contributing gametes to the next generation in an idealized theoretical population, and may be considered as a measure of the increase of homozygosity because of common ancestry, or a measure of gene-frequency drift (Crow \& Kimura, 1970; Crow \& Denniston, 1988). In an ideal population genotypic frequencies and the level of genetic variation are constant in consecutive generations and a population is in Hardy-Weinberg equilibrium. Nevertheless, in most cases, migration, selection, mutation and restriction of the breeding population cause directional or stochastic changes in allele frequencies among generations. Some types of mating systems could also cause differences in allele frequencies; however, a constant amount of consanguineous mating does not influence allele frequencies (Crow \& Kimura, 1970), rather, finite size of a population or differential contribution of parents may do this.
A finite population experiences drift leading to increased homozygosity. In an idealized model an observed increase in homozygosity from one generation to the next can be attributed to a specific finite population size, this being referred to as the 'inbreeding effective population size'. The sampling variance of allele frequency change from mature to filial generations is also dependent on population size. If one assumes that all the observed variance in allele frequencies between generations is because of finite population size, 'variance effective population size' can be estimated (Crow \& Kimura, 1970).

Conifers are valuable model organisms for studying mating systems because of the high levels of genetic variation observed in isozyme studies (Ledig, 1986), and because of the ability to identify separately the genotypes of the maternal and paternal gametes contributing to an embryo (Adams, 1983). Mating system analyses of populations based on isozyme markers, however, often exhibit differences among mating system parameters estimated for different loci (Mitton, 1992), which is likely to be observed especially when small sample sizes are 
analysed (Brown et al., 1985). Müller-Starck \& Gregorius (1988), for example, studying the mating system of a Scots pine seed orchard composed of two clones, showed that each of the three studied loci could suggest a different type of mating system. When variance effective population sizes are estimated from allele frequencies (Waples, 1989) based on several loci some of them may have a major impact on the overall variance, whereas the influence of others is minor. Thus it is interesting to study the variance effective population size when all investigated loci are analysed at once. Considering several unlinked neutral loci, all multilocus associations are affected by genetic drift to the same extent and therefore provide information relevant to an estimate of effective population size (Waples, 1991). In this way the frequencies of multilocus gamete types contributed to a filial generation could be compared with the expected frequencies of the corresponding gametes produced by a mature generation following meiosis. If all adult individuals in a population produce equal numbers of male and female gametes, then the frequencies of multilocus gamete types contributing to the filial generation should be similar to those expected to be produced by the parents.

The estimation of effective population size is especially important for forest seed orchards. When the effective population size of an orchard is small, the genetic composition of the seed crop may be different from that expected from the genetic composition of the clones in the orchard. The purpose of this study was to employ a multilocus gametic frequency method for estimating variance effective population size in a Scots pine (Pinus sylvestris L.) seed orchard based on allozyme data obtained from the progeny.

The multilocus gametic frequency model introduced here is an expansion of the single-locus method presented by Roberds et al. (1991). The two methods can be employed only when the haploid genotypes of both the male and female gametes of seeds can be determined, as in conifers. In addition, they should be used in isolated populations, where the expected frequencies of alleles or gamete types can be calculated exactly, on the basis of the genotypic composition of adults.

\section{Materials and methods}

\section{Studied population and biochemical analyses}

The Gniewkowo clonal seed orchard was established in 1972 and consists of 32 clones derived from selec- ted Scots pine plus trees growing in the Tuchola Forests in Poland. The orchard is surrounded by fields and the nearest Scots pine stands are located about $1 \mathrm{~km}$ away towards the north-west. The orchard consists of three blocks, each containing all 32 clones, but with different numbers of ramets per clone, and different randomizations of clone positions (Burczyk, 1990). For this investigation, cones were collected from a single ramet of each clone during autumn 1988 in one of the orchard blocks. Later analysis revealed that the clonal identity of five of the ramets had been mislabelled; five clones were not represented in the sample whereas a few clones were represented by multiple ramets. Allele frequencies and expected multilocus gamete frequencies in the parental population were calculated from the known genotypes of the 32 clones (Burczyk, 1992). An equal number of 40 seeds per ramet (embryo and megagametophyte tissues) was assayed electrophoretically according to Yeh \& O'Malley (1980). Three enzyme systems were stained: glutamate dehydrogenase (EC 1.4.1.2; $\mathrm{GDH}$ ), glutamate-oxaloacetate transaminase (EC 2.6.1.1; GOT) and malate dehydrogenase (EC 1.1.1.37; MDH), and four unlinked loci ( $G d h$, Got-2, Got-3, Mdh-3) were scored (Niebling et al., 1987; Szmidt \& Muona, 1989).

\section{Estimation of variance effective population size}

The effective size of the progeny population was estimated based on both gametic and allelic frequency methods. Because of the sampling method, where an equal number of seeds was analysed per maternal parent, only male gametes can be considered as sampled at random. Thus, only the variance effective population size attributable to paternal contribution can be estimated.

Estimation of the effective number based on allele frequencies followed the method of Roberds et al. (1991), but was modified slightly to allow for the analysis of multiple alleles per locus, in a similar way to Cheliak et al. (1985). The variance effective number of gametes contributed to the sampled progeny by pollen parents for the entire orchard was estimated as:

$\hat{N}_{\mathrm{e}(p)}=\frac{(d n-1)}{2\left(f_{(p)} d n-1\right)}$,

where $d$ is the number of progeny analysed per ramet, $n$ is the number of ramets sampled and $f_{(p)}$ is the standardized variance of allele frequency change in the pollen pool of the entire orchard, which can 
be obtained from:

$\hat{f}_{(p)}=\frac{1}{w} \sum_{m=2}^{M} \frac{m-1}{m} \sum_{j_{(m)}=1}^{x_{(m)}} \sum_{i=1}^{m} \frac{\left(q_{i j_{(m)}}-p_{i j_{(m)}}\right)^{2}}{p_{i j_{(m)}}\left(1-p_{i j(m)}\right)}$.

Here $q_{i j(m)}$ indicates the frequency of the $i$ th allele at the $j$ th locus with $m$ alleles observed in the pollen gametes contributed into the progeny and $p_{i j(m)}$ is the analogous frequency observed in the mature population. The coefficient $w$ is the number of independent alleles summed over all loci (Cheliak et al., 1985) and is expressed as:

$w=\sum_{m=2}^{M}(m-1) x_{(m)}$,

where $x_{(m)}$ is the number of loci with $m$ alleles and $M$ is the maximum number of alleles observed among the loci studied.

The effective number of gametes of pollen parents for each sampled ramet is given by:

$\hat{N}_{\mathrm{e}(k) t}=\frac{(d-1)}{2\left(f_{(k) t} d-1\right)}$,

where $f_{(k) t}$ is the standardized variance of allele frequencies in the pollen gametes of the progeny of the $t$ th sampled ramet and can be obtained from eqn 2 by substituting $q_{i j(m) t}$ instead of $q_{i j(m)}$, where $q_{i j(m) t}$ is the frequency of the $i$ th allele at the $j$ th locus with $m$ alleles observed in the pollen gametes of the progeny of the $t$ th ramet.

An estimator for the effective number of pollen gametes for individual ramets for the entire orchard $\left(\hat{N}_{\mathrm{e}(k)}\right)$ can be calculated from eqn 4 , where $f_{(k) t}$ is substituted by $f_{(k)}$, and

$\hat{f}_{(k)}=\frac{1}{n} \sum_{t=1}^{n} f_{(k) t}$

where $n$ is the total number of ramets analysed. Thus $\hat{f}_{(k)}$ is an average value of $\hat{f}_{(k) t}$ across $n$ ramets.

The difference between the estimation of gametic frequency variance effective population size and that based on allele frequencies lies in the standardized variance equations. The gametic frequency (multilocus) model may be considered as a specific case of one locus with $m$ alleles. The standardized variance of change in multilocus gamete frequencies in the pollen pool of the entire orchard can be expressed as:

$\hat{f}_{\mathrm{m}(p)}=\frac{1}{x} \sum_{i=1}^{x} \frac{\left(e_{i}-g_{i}\right)^{2}}{g_{i}\left(1-g_{i}\right)}$, where $e_{i}$ is the frequency of the $i$ th multilocus gamete type observed in the pollen pool of the progeny, $g_{i}$ is the expected frequency of that gamete type based on the genotypic composition of the orchard ramets (see next section) and $x$ is the total number of multilocus gamete types that could be produced by the orchard.

The analogous variance used in the estimation of the effective number of pollen gametes for individual ramets, and for individual ramets for the entire orchard $\hat{f}_{\mathrm{m}(k) t}$ may be obtained from eqn 6 by substituting $e_{i t}$ instead of $e_{i}$, where $e_{i t}$ is the frequency of the $i$ th multilocus gamete type observed in the progeny of the $t$ th maternal tree. The substitution of $\hat{f}_{\mathrm{m}(p)}$ and $\hat{f}_{\mathrm{m}(k) !}$ instead of $\hat{f}_{(p)}$ and $\hat{f}_{(k) t}$ in eqns 1,4 and 5 allows the estimation of the respective effective numbers based on multilocus gametic frequency data.

Ninety-five per cent confidence intervals (CI) for $\hat{N}_{\mathrm{e}}$ were calculated according to Roberds et al. (1991); however, to calculate degrees of freedom the number of independent alleles $(w)$ or the number of possible multilocus gamete types less one $(x-1)$ were used, depending on the model, instead of the number of loci. Negative values for $\hat{N}_{\mathrm{e}}$ or for endpoints of confidence intervals were interpreted as infinite effective numbers (see: Waples, 1989; Roberds et al., 1991, and references therein).

\section{Calculation of the expected frequencies of multilocus gamete types}

The expected frequency, $g_{i}$, of each haploid gamete type $G_{i}$ in the seed crop assumes that each clone (and each ramet within a clone) contributes with equal probability male and/or female gametes to the seed sample (equal male and/or female fertility), and that each clone has an equal probability of mating with all other clones (equal pairwise mating probabilities) (Schoen \& Stewart, 1987). Under these assumptions the expected frequency of each multilocus gamete type can be calculated according to Schoen \& Cheliak (1987):

$\hat{g}_{i}=\frac{1}{N} \sum_{j} R_{i, j} n_{j}$,

where $R_{i, j}$ is the probability that diploid genotype $j$ produces haploid gamete $i$ by meiosis (Table 1$), n_{j}$ is the number of clones (or ramets) with diploid genotype $j$, and $N$ is the total number of possible parents (clones or ramets). The absence of detectable linkage among loci simplifies the estimation; however, if linkage relationships were known, 


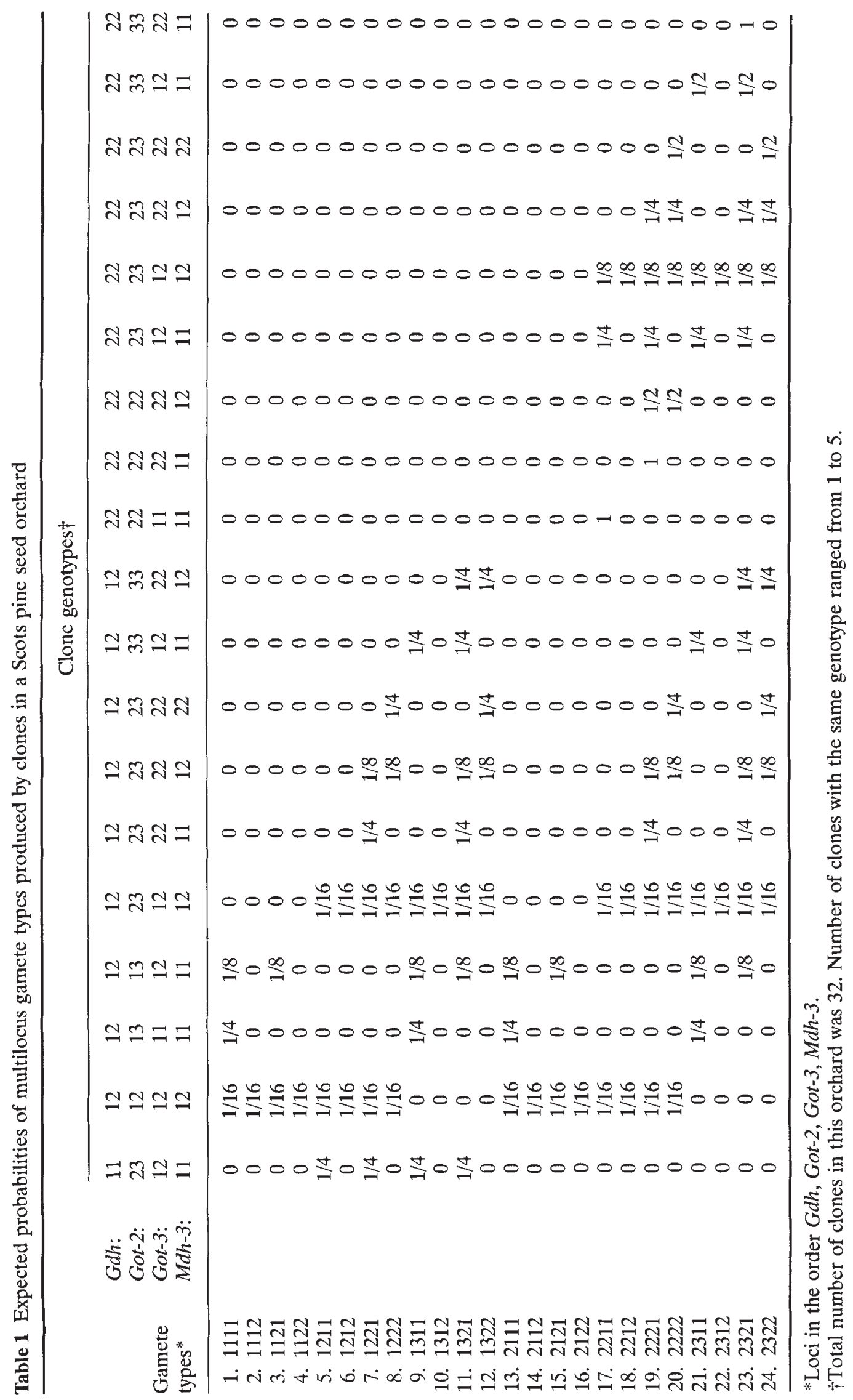


specific $R_{i, j}$ could be calculated (Schoen \& Stewart, 1986). In this study, the mature population of possible parents was considered as the set of all 1056 ramets growing in the orchard.

\section{Results}

Analysis of the orchard clones showed that there were 19 different four-locus diploid genotypes among the 32 clones, of which 12 genotypes were unique to individuals (Table 1). These clones are able to produce a total of $x=24$ different four-locus gametic types, on the basis of genotypic structure.

The gametic frequency effective population size of the progeny population which may be attributed to the contribution of pollen parents was estimated for the entire orchard to be 105.30 , whereas the estimates for individual ramets ranged from 9.13 to infinity (Table 2). The orchard-wide estimate of $\hat{N}_{\mathrm{e}}$ for individual ramets based on the gametic frequency analysis was 41.79 . Comparable estimates based on allele frequencies were 156.66 for the entire orchard, 5.80 to infinity for individual ramets and 47.80 for individual ramets when considered orchard-wide. However, the difference between the estimates calculated for the entire orchard by the different methods was found to be statistically insignificant (based on confidence intervals; Table 2). In both cases, orchard-wide estimates of $\hat{N}_{\mathrm{e}}$ for individual ramets were about three times less than estimates calculated for the entire orchard.

Effective numbers could be determined for 19 ramets when allele frequency data were used, and for 25 ramets when gametic frequency data were applied. Because some of the effective numbers were estimated to be negative, the standardized variances rather than effective numbers were compared between the two methods. The standardized variances obtained for each ramet, on the basis of allele and gametic frequencies, were significantly correlated $(r=0.373 ; P=0.035)$ across the sampled trees.

\section{Discussion}

It is obvious that when gametes are considered as sets of unlinked genes and when the frequencies of such multilocus gamete types contributing to the progeny are similar to expectation because of panmixis, assuming equal male and female fertility, the allele frequencies are constant between generations and a population is in a Hardy-Weinberg equilibrium. Analogously, the genetic drift of allele frequencies determines the drift between the observed and expected frequencies of multilocus gametes contributing to the progeny. In this way we can compare observed and expected gamete frequencies and make inferences about the variance effective population size in terms of the drift variance in gamete frequencies. Variance effective numbers based on allelic and multilocus gametic data, however, are defined in different terms (drift variance in allele frequencies, or drift variance in gamete frequencies), but they are both influenced by the same hypothetical real variance effective size of a population.

The variance effective population size of the orchard estimated in this study indicates that the male gamete pool fertilizing the analysed embryos is equivalent to the breeding population consisting of 105 or 157 individuals, depending on the model applied (gametic or allelic). Because the sampling variance depends on the size of the sample, i.e. the number of offspring, the variance effective number should be related to the number in the progeny generation (Crow \& Kimura, 1970). Then the ratio of effective population number to the census one $\left(\hat{N}_{\mathrm{e}} \cdot / N\right)$ in the progeny equals 0.0823 for the gametic frequency, and 0.1224 for the allelic frequency method, which should be considered to be rather small. The orchard-wide $\hat{N}_{\mathrm{e}(k)}$ estimates (42 or 48; Table 2) were very close to the number of seeds sampled per ramet $(d=40)$. Some of the $\hat{N}_{\mathrm{e}(k) t}$ estimates (or CI) obtained for individual ramets were found to be infinite (Table 2). Waples (1989) noted that trials for which standardized variances $(\hat{f})$ were very small lead to unusual results $\left(\hat{N}_{\mathrm{e}}=\infty\right.$ or negative). In the present study this could happen if, using eqn $4, \hat{f}_{(k) t} \leq[1 / d]$ (allelic method) or $\hat{f}_{\mathrm{m}(k) t} \leq[1 / d]$ (gametic method). Equation 4 can be transformed to the form $\hat{N}_{\mathrm{e}}=(1-1 / d) /(2(f-1 / d))$. Here, the quantity $[1 / d]$ accounts for the expected 'spurious' contribution to $\hat{f}$ that results from taking a finite sample of individuals for analysis. If $\hat{f} \leq[1 / d]$, all of the temporal differences can be explained by sampling error without invoking genetic drift at all (Waples, 1989). In such a case there is no evidence that $N_{\mathrm{e}}$ is lower than the census population, and in practice we should not worry that $N_{\mathrm{e}}$ is substantially reduced.

Roberds et al. (1991) indicated that the two potential factors decreasing $\hat{N}_{\mathrm{e}}$ in seed orchards are background pollination and imbalanced paternal contribution. Although the expected paternal contribution, as revealed by the inbreeding effective number estimate, on the basis of flowering data ( 24 individuals among 32 clones; J. Burczyk \& W. Chałupka, unpublished data), was rather balanced, the proportion of detected contaminants in the studied material, on the basis of 10 loci, was 
Table 2 Estimates of effective numbers of pollen gametes (paternal contribution) for sampled trees with confidence intervals in a Scots pine seed orchard when all the orchard was considered as a possible paternal population (40 seeds sampled per tree, 1280 in total)

\begin{tabular}{|c|c|c|c|c|c|c|}
\hline \multirow{3}{*}{$\begin{array}{l}\text { Sampled } \\
\text { tree } \\
\text { number }\end{array}$} & \multicolumn{3}{|c|}{$\begin{array}{l}\text { Allele frequency } \\
\text { data }\end{array}$} & \multicolumn{3}{|c|}{$\begin{array}{l}\text { Multilocus gametic } \\
\text { frequency data }\end{array}$} \\
\hline & \multirow[t]{2}{*}{$\begin{array}{l}\text { Effective } \\
\text { number }\end{array}$} & \multicolumn{2}{|c|}{$\begin{array}{l}95 \% \text { confidence } \\
\text { intervals }\end{array}$} & \multirow[t]{2}{*}{$\begin{array}{l}\text { Effective } \\
\text { number }\end{array}$} & \multicolumn{2}{|c|}{$\begin{array}{l}95 \% \text { confidence } \\
\text { intervals }\end{array}$} \\
\hline & & & & & & \\
\hline 210 & 230.65 & 3.53 & $\infty$ & $\infty$ & 45.92 & $\infty$ \\
\hline 211 & 13.11 & 1.40 & $\infty$ & 17.14 & 6.22 & 64.32 \\
\hline 212 & 28.32 & 2.13 & $\infty$ & $\infty$ & 33.49 & $\infty$ \\
\hline 213 & $\infty$ & 18.11 & $\infty$ & $\infty$ & 28.98 & $\infty$ \\
\hline 214 & 57.88 & 2.77 & $\infty$ & 24.49 & 7.87 & 204.92 \\
\hline 215 & $\infty$ & 7.95 & $\infty$ & $\infty$ & 50.83 & $\infty$ \\
\hline 216 & 17.79 & 1.86 & $\infty$ & 9.13 & 3.85 & 21.37 \\
\hline 217 & $\infty$ & 5.30 & $\infty$ & 17.60 & 6.33 & 68.38 \\
\hline 218 & 64.93 & 2.86 & $\infty$ & 35.81 & 9.80 & $\infty$ \\
\hline 219 & 54.76 & 2.72 & $\infty$ & 90.96 & 14.44 & $\infty$ \\
\hline 220 & 165.41 & 3.41 & $\infty$ & 1590.26 & 20.33 & $\infty$ \\
\hline 221 & 84.48 & 3.04 & $\infty$ & 67.70 & 13.06 & $\infty$ \\
\hline 222 & 17.23 & 1.65 & $\infty$ & 13.81 & 5.32 & 41.44 \\
\hline 223 & 10.69 & 1.22 & 194.79 & 52.66 & 11.80 & $\infty$ \\
\hline 224 & 28.17 & 2.12 & $\infty$ & 36.83 & 9.95 & $\infty$ \\
\hline 225 & $\infty$ & 6.21 & $\infty$ & 52.17 & 11.76 & $\infty$ \\
\hline 226 & 5.80 & 0.77 & 27.88 & 43.92 & 10.87 & $\infty$ \\
\hline 227 & $\infty$ & 4.16 & $\infty$ & 48.30 & 11.36 & $\infty$ \\
\hline 228 & 664.71 & 3.75 & $\infty$ & 193.84 & 17.26 & $\infty$ \\
\hline 229 & $\infty$ & 5.45 & $\infty$ & 782.38 & 19.83 & $\infty$ \\
\hline 230 & $\infty$ & 6.95 & $\infty$ & $\infty$ & 20.78 & $\infty$ \\
\hline 231 & $\infty$ & 6.28 & $\infty$ & $\infty$ & $\infty$ & $\infty$ \\
\hline 232 & $\infty$ & 4.69 & $\infty$ & 28.57 & 8.64 & 756.56 \\
\hline 233 & 1165.60 & 3.81 & $\infty$ & 76.23 & 13.63 & $\infty$ \\
\hline 234 & $\infty$ & 4.11 & $\infty$ & 16.21 & 5.97 & 56.81 \\
\hline 235 & $\infty$ & 3.89 & $\infty$ & 59.94 & 12.46 & $\infty$ \\
\hline 236 & $\infty$ & 14.62 & $\infty$ & 12.77 & 5.01 & 36.06 \\
\hline 237 & $\infty$ & 5.67 & $\infty$ & 60.45 & 12.50 & $\infty$ \\
\hline 238 & 28.57 & 2.14 & $\infty$ & 63.37 & 12.74 & $\infty$ \\
\hline 239 & 5.92 & 0.78 & 28.94 & 13.12 & 5.11 & 37.78 \\
\hline 240 & 431.20 & 3.69 & $\infty$ & $\infty$ & 32.64 & $\infty$ \\
\hline 241 & 20.79 & 1.83 & $\infty$ & 40.73 & 10.47 & $\infty$ \\
\hline Orchard-wide & 47.80 & 25.14 & 135.37 & 41.79 & 31.19 & 59.03 \\
\hline Orchard level & 156.66 & 21.62 & 652.40 & 105.30 & 50.40 & 193.05 \\
\hline
\end{tabular}

observed to be 17.7 per cent (Burczyk, 1992). It seems that the multilocus gametic frequency approach is better suited to situations in which background pollination is a factor affecting mating patterns of a population. Multilocus techniques permit a greater proportion of contaminant male gametes to be detected and discarded from the analysis than do single locus methods, where only rare alien alleles could be noticed; however, because of a small number of loci applied it was not the case in this study. If contamination occurs, and if the allele frequencies in surrounding forests are similar to those observed in an orchard (which is common in conifers), the standardized variance and conse- 
quently $\hat{N}_{\mathrm{e}}$, calculated on the basis of the allelic frequency method, will not be affected by contamination. In contrast, because of a finite number of diploid genotypes, frequencies of multilocus gamete types produced by an orchard could be quite different from the frequencies of corresponding gametes produced by surrounding stands. Thus, background pollination may increase the standardized variance and decrease the $\hat{N}_{\mathrm{e}}$ estimate obtained from the gametic frequency approach. The lower gametic frequency estimates found in the present study may support this hypothesis; however, despite the contamination detected in the studied orchard the $\hat{N}_{\mathrm{e}}$ estimate has some important meaning. The contamination decreases the proportion of pollen produced by an orchard. In such a case, although the possible number of pollen donors (including background stands) may be large, the effective number of pollen parents within an orchard is further decreased. Accordingly, the $\hat{N}_{\mathrm{e}} / N$ ratio may be considered as a measure of the efficiency of an orchard in the transmission of genetic information to the progeny generation (Roberds et al., 1991).

The two methods gave quite similar results (nonsignificant differences for orchard-wide and orchard level estimates, significant correlation between standardized variances), but the gametic frequency estimates of variance effective population sizes may have some advantages compared with those based on allele frequencies. Apart from the possibility of detecting contaminant gametes, discussed above, the gametic frequency model gives more precise estimates in terms of narrower confidence intervals (Table 2). In the studied case, there were 24 frequency pairs (observed and expected gamete frequencies) used in the calculations when a gametic frequency model was employed (eqn 6), whereas only nine frequency pairs (three loci with two alleles, and one locus with three alleles) were used when allele frequencies were utilized (eqn 2). Thus more information per observation is available from multilocus gametic frequency data. Waples (1989) indicated that the accuracy and precision of $\hat{N}_{\mathrm{e}}$ estimates are greater when the number of alleles and the number of loci studied are increased. In the same orchard the $\hat{N}_{\mathrm{e}}$ has already been investigated based on the allelic method using 10 loci (28 alleles in total) for one-half of the same studied material (640 seeds; Burczyk, 1992). $N_{\mathrm{e}}$ was estimated to be 55 (CI: $23-112$ ), and the ratio $\hat{N}_{\mathrm{e}} / N$ in the progeny population was calculated to be 0.0859 , which is nearly identical to the ratio obtained in the present study, on the basis of the gametic frequency method. This may suggest that similar results (in terms of the
$\hat{N}_{\mathrm{e}} / N$ ratio) can be achieved when $N_{\mathrm{e}}$ is estimated using many loci with multiple alleles or when multilocus gametic frequency data of a few loci are used, although the different sample sizes could also have an effect.

Effective population size has rarely been investigated in conifer seed orchards. For two Finnish Scots pine seed orchards the ratio of inbreeding effective population size to the actual population size was $0.66(18.5 / 28)$ and $0.93(23.2 / 25)$ (Muona \& Harju, 1989). Stern \& Gregorius (1972) in a 70-yearold stand of Scots pine calculated the ratio to be $0.46,0.55$ and 0.61 in three consecutive years. In a black spruce seed orchard, the ratio of the variance effective number of individuals to the actual one was found to be very small and was calculated to be $0.07(4 / 60)$ for males and $0.22(13 / 60)$ for females (Barrett et al., 1987). The variance effective numbers for Douglas fir and loblolly pine orchards were calculated to be 310.46 and 16.47 , respectively, when sampling 315 seeds in the Douglas fir and 1008 seeds in the loblolly pine seed orchards. Considerable variation among clones was observed in the Douglas fir but not in the loblolly pine seed orchard (Roberds et al., 1991). The differences between the two orchards were mainly explained by the extent of background pollination (lower in the Douglas fir) and phenology differences among clones, which could result from a specific treatment (water spray cooling) of the Douglas fir seed orchard (Roberds et al., 1991). Although, different estimation procedures make comparison between the published and the present results difficult, the estimates obtained by Barret et al. (1987) indicated reduced variance effective numbers similar to this study. Comparison between the inbreeding and variance effective numbers is very difficult, however, unless population sizes are constant in consecutive generations, and sampling is made in the same life stages (Crow \& Kimura, 1970; Waples, 1989). It is even more difficult in this study because the inbreeding and variance effective numbers were calculated in different ways: on the basis of potential (flowering) and realized (pollen gamete genotypes) paternal contributions, respectively. Thus, a number of factors which influence male reproductive success (besides floral fecundity) may also cause the difference between the observed inbreeding and variance effective numbers.

Genetic variation in male and female flowering and fruiting has often been studied in conifer seed orchards (Jonsson et al., 1976; Muona \& Harju, 1989), and in recent years, male and female fertility variation has been investigated at the progeny level, 
based on isozyme analyses, and attempts have been made to characterize mating systems (Müller-Starck, 1982; Schoen \& Stewart, 1987; Adams \& Birkes, 1989). These studies have revealed nonuniform contributions of clones to orchard progeny. The present results for the variance effective population size, on the basis of multilocus gametic frequency, do not determine the contribution of particular clones, but they may be useful for characterizing seed orchard effectiveness.

As pointed out by Nei \& Tajima (1981), the temporal method, which was used in this study, is especially precise (narrow confidence intervals) for small effective sizes. This may be observed when the estimates for sampled ramets are considered (Table 2). The method should be useful therefore for conservation biology where small effective population sizes may increase the effect of inbreeding depression and may cause loss of genetic variability (Waples, 1989), and it is well suited for use in seed orchards (Roberds et al., 1991). Thus, if $N_{\mathrm{e}}$ of a seed orchard is considerably restricted compared with the census population, this should be easily detected using the temporal method. The eventual small ratio of effective to actual population sizes in orchards reduces the genetic value of seeds. Knowledge about the different contributions of clones to total gamete production and about the effective population size is important when breeders make assumptions about the genetic composition expected in the progeny populations used for reforestation.

It would be interesting to estimate the mean variance effective population size for both male and female gametes contributed to the sampled progeny. This could be achieved by calculating harmonic means for male and female effects (Crow \& Kimura, 1970). Because equal numbers of seeds per individual ramet were sampled, we should expect the variance effective population size of ovule gametes to be large $\left(N_{\mathrm{e}} \approx 1280\right.$, and the ratio $\left.N_{\mathrm{e}} / \mathrm{N} \approx 1\right)$, unless linkage or segregation distortions were involved. In fact, when the gametic frequency method was applied to female gametes contributed to the sampled seeds (expected multilocus gamete frequencies, eqn 6 , were calculated based on the genotypic composition of sampled ramets), the effective number was estimated to be 2165.20 (CI: $424.40-\infty$ ). Then, if we use 105.3 and 1280 (to simplify) for the effective numbers of male and female gametes, respectively, the harmonic mean $N_{\mathrm{e}}=194.36$. This indicates clearly that the mode of seed collection (balanced or not) from individual trees or clones may affect final variance effective numbers and this should be considered in forestry practices.

It might be expected that the precision of the multilocus estimate would greatly increase if some additional loci were used. The sampling strategies (minimum sample sizes for parental and filial generations), the properties of the proposed multilocus gametic frequency estimator, and the relationship between variance and inbreeding effective numbers need to be further investigated for a wider variety of breeding systems.

\section{Acknowledgements}

The author thanks W.T. Adams, J.H. Roberds, R.S. Waples and two anonymous referees for their helpful comments and suggestions on an earlier draft. This work was supported by the Institute of Dendrology, Polish Academy of Sciences, and in part by Research Grant No. 5 P06M 01508 from the State Committee for Science and Research, Poland. The final stage of this paper was prepared when the author received the award fellowship from the Foundation for Polish Science.

\section{References}

ADAMS, w. T. 1983. Application of isozymes in tree breeding. In: Tanksley S. D. and Orton, T. J. (eds) Isozymes in Plant Genetics and Breeding, Part A, pp. 381-400. Elsevier Publishing B.V., Amsterdam.

ADAMS, w. T. AND BIRKES, D. S. 1989. Mating patterns in seed orchards. In: Proceedings of the 20th Southern Forest Tree Improvement Conference, June 26-30, 1989, pp. 75-86. Southern Forest Tree Improvement Committee, Charleston, SC.

BARRETT, J. W., KNOWles, P. AND CHELIAK, w. M. 1987. The mating system in a black spruce clonal seed orchard. Can. J. Forest Res., 17, 379-382.

BROWN, A. H. D., BARRETT, S. C. H. AND MORAN, G. F. 1985. Mating system estimation in forest trees: models, methods and meanings. In: Gregorius, H.-R. (ed.) Population Genetics in Forestry, pp. 32-49. SpringerVerlag, Berlin.

BURCZYK, J. 1990. Struktura genetyczna plantacji nasiennej sosny zwyczajnej (Pinus sylvestris L.) w Nadleśnictwie Gniewkowo. Arboretum Kórnickie, 35, 91-103.

BURCZYK, J. 1992. System Kojarzenia a Fenologia $i$ Intensywność Kwitnienia na wybranej Plantacji nasiennej Sosny zwyczajnej (Pinus sylvestris L.). Ph.D. Thesis, University of A. Mickiewicz, Poznań.

CheliaK, w. M., PITEl, J. A. AND murray, G. 1985. Population structure and mating system of white spruce. Can. J. Forest Res., 15, 301-308.

CROW, J. F. AND DENNISTON, C. 1988. Inbreeding and variance effective population numbers. Evolution, 42, $482-495$. 
Crow, J. F. AND kimura, M. 1970. An Introduction to Population Genetics Theory. Harper \& Row, New York.

JONSSON, A., EKBERG, 1. AND ERIKSSON, G. 1976. Flowering in a seed orchard of Pinus sylvestris L. Stud. Forest. Suec., 135, 1-38.

LEDIG, F. T. 1986. Heterozygosity, heterosis, and fitness in outbreeding plants. In: Soulé, M. E. (ed.) Conservation Biology: the Science of Scarcity and Diversity, pp. 77-104. Sinauer, Sunderland, MA.

mitTon, J. B. 1992. The dynamic mating system of conifers. New Forests, 6, 197-216.

MUONA, O. AND HARJU, A. 1989. Effective population sizes, mating system and genetic variability in Scots pine natural populations and seed orchards. Silvae Genet., 38, 221-228.

MÜLLER-STARCK, G, 1982. Sexual asymmetric fertility selection and partial self-fertilization. 2. Clonal gametic contributions to the offspring of a Scots pine seed orchard. In: Proceedings of the Symposium on Population Genetics of Forest Trees, Helsinki 1981. Silva Fenn., 16, 99-106.

MÜllER-STARCK, G. AND GREGORIUS. H.-R. 1988. Analysis of mating systems in forest trees. In: Weir, B. S., Eisen, E. J., Goodman, M. M. and Namkong G. (eds) Proceedings of the Second International Conference on 'Quantitative Genetics', pp. 573-597. Sinauer, Sunderland, MA.

NEl, M. AND TAJIMA, F. 1981. Genetic drift and estimation of effective population size. Genetics, 98, 625-640.

NIEBLING, C. R., JOHNSON, K. AND GERHOLD, H. D. 1987. Electrophoretic analysis of genetic linkage in Scots pine (Pinus sylvestris L.). Biochem. Genet., 25, 803-814.
ROBERDS, J. H., FRIEDMAN, S. T. AND EL-KASSABY, Y. A. 1991. Effective number of pollen parents in clonal seed orchards. Theor. Appl. Genet., 82, 313-320.

SCHOEN, D. J. AND CHEliAK, w. M. 1987. Genetics of the polycross. 2. Male fertility variation in Norway spruce, Picea abies (L.) Karst. Theor. Appl. Genet., 74, 554-559.

SCHOEN, D. J. AND STEWART, S. C. 1986. Variation in male reproductive investment and male reproductive success in white spruce. Evolution, 40, 1109-1120.

SCHOEN, D. J. AND STEWART, s. C. 1987. Mating system variation in a clonal white spruce seed orchard. Clonal male fertilities and mating patterns. Genetics, 116, 141-152.

STERN, K. AND GREGORIUS, H.-R. 1972. Schatzungen der effektiven Populationsgrosse bei Pinus sylvestris. Theor. Appl. Genet., 42, 107-110.

SZMIDT, A. E. AND MUONA, O. 1989. Linkage relationships of allozyme loci in Pinus sylvestris. Hereditas, 111, 91-97.

WAPLES, R. S. 1989. A generalized approach for estimating effective population size from temporal changes in allele frequency. Genetics, 121, 379-391.

WAPLES, R. S. 1991. Genetic methods for estimating the effective size of cetacean populations. Rep. Int. Whal. Commun., 13, 279-300.

YEH, F. C. AND O'MALlEY, D. M. 1980. Enzyme variation in natural populations of Douglas fir (Pseudotsuga menziesii [Mirb.] Franco.) from British Columbia. I. Genetic variation patterns in coastal populations. Silvae Genet., 29, 83-92. 